\title{
Sistem Pendukung Keputusan Penilaian Kinerja Karyawan Pada PT Manggala Usaha Manunggal Menggunakan Metode Analytical Hierarchy Process (AHP)
}

\author{
Sella Marta Armelia \& Firamon Syakti \\ Fakultas Ilmu Komputer, Universitas Bina Darma \\ Email: sellamarta14@gmail.com
}

\begin{abstract}
PT Manggala Usaha Manunggal is a company engaged in mining and focusing on coal minerals, which is supported by many employees who work professionally in their respective fields. In a company, an employee performance appraisal process is usually carried out to determine the best employees. In the current performance appraisal process, the company still uses a manual system, so it is still less effective and efficient in managing data. The problem faced is how to calculate the best employee performance appraisal, with a decision support system in calculating employee performance appraisal, one of which is by applying the AHP (Analytical Hierarchy Porcess) method which is expected to produce the best employee rankings. The system that will be created will be web-based using MYSQL.
\end{abstract}

Keywords: Decision support system, Performance Assessment, AHP Method, MYSQL

\section{Pendahuluan}

Kemajuan teknologi informasi semakin berkembang dalam segala aspek kehidupan, salah satunya ialah mempermudah pekerjaan manusia dalam kehidupan sehari-hari. Sekarang ini manusia mulai mengembangkan sistem yang dapat membantu menentukan alternatif terbaik dalam sebuah permasalahan, ialah sistem pendukung keputusan (SPK). Di dalam sebuah SPK terdapat alternatif, kriteria dan bobot yang digunakan untuk menentukan solusi terbaik. Karyawan merupakan salah satu faktor untuk menunjang suatu kemajuan dalam sebuah instansi perusahaan untuk mencapai tujuan dan sasaran yang telah ditentukan. Maka dari itu karyawan yang berkopetensi tinggi yang dapat mendukung tingkat kinerja, dengan dilakukan penilaian kinerja dapat diketahui prestasi yang dicapai setiap karyawan. Dalam sebuah perusahaan biasanya memiliki standar mutu untuk mengukur keberhasilan kinerja karyawan, namun kualitas kerja dari karyawan tidak selamanya sesuai dengan standar mutu yang ada, hal ini dapat digunakan sebagai pertimbangan oleh perusahaan dalam menentukan karyawan terbaik.

PT Manggala Usaha Manunggal adalah perusahaan yang bergerak di bidang pertambangan dan fokus pada mineral batubara. Dalam melakukan proses usahanya PT Manggala Usaha Manunggal memiliki karyawan kurang lebih sebanyak 240 orang yang terdiri dari karyawan kontrak dan karyawan tetap yang bekerja secara profesional dalam bidangnya masing-masing.

Penilaian kinerja karyawan merupaka kegiatan rutin yang dilakukan oleh PT Manggala Usaha Manunggal dalam rangka untuk meningkatkan mutu kinerja karyawan, biasanya proses penilaian kinerja karyawan dilakukan minimal 2 kali dalam setahun. Namun dalam proses penilaian kinerja selama ini masih secara manual, belum menggunakan sistem dan membutuhkan waktu yang lama dalam mengelola data penilaian kinerja karyawan. 
Berdasarkan masalah diatas, dibutuhkan proses penilaian kinerja karyawan dengan menggunakan sistem yang bertujuan mempermudah proses penilaian kinerja pada perusahaan yang nantinya proses penilaian kinerja terbagi menjadi dua yaitu penilaian untuk karyawan tetap dan kontrak. Dalam penilaian dihitung menggunakan metode Analytical Hierarchy Process (AHP) untuk menentukan bobot dari kriteria yang telah ditentukan. Sistem yang akan dibuat nantinya berbasis Web menggunakan PHP (Hypertext Preprocesor) dan MYSQL (My Structured Query).

\section{Tinjauan Literatur}

\subsection{Metode Analytical Hierarchy Process (AHP)}

Analytical Hierarchy Process (AHP) adalah suatu metode atau model untuk pendukung keputusan yang dikembangkan oleh Thomas L. Saaty. Model pendukung keputusan akan menguraikan suatu masalah dari multi faktor atau multi kriteria yang kompleks untuk menjadi suatu hirarki, hirarki didefinisikan sebagai suatu representasi dari sebuah permasalahan yang kompleks dalam suatu struktur multi level dimana level yang pertama ialah tujuan, yang diikuti level faktor, kriteria, sub kriteria, hingga seterusnya ke bawah sampai level terakhir dari alternatif. Hirarki memiliki fungsi agar menguraikan suatu permasalahan ke dalam kelompok-kelompoknya sehingga nantinya dibuat menjadi suatu bentuk hirarki untuk menghasilkan Suatu permasalahan untuk terlihat lebih terstruktur (Alvioletta, Setyawan, \& Saputra, 2020).

\subsection{Unifield Modeling Languange (UML)}

Menurut pendapat (Ginting, Tahun 2013) "Unified Modeling Language (UML) merupakan Bukan sebuah suatu proses, melainkan bahasa pemodelan secara grafis untuk dapat menspesifikasikan, memvisualisasikan, membangun, serta mendokumentasikan seluruh sistem perangkat lunak yang dibuat. Penggunaan model UML bertujuan untuk mengidentifikasikan bagian yang termasuk ke dalam sebuah lingkup sistem yang dibahas serta bagaimana hubungan antara sistem yang dibuat dengan subsistem maupun sistem lainyaa." (Heriyanto, 2018)

\subsection{MYSQL}

Dalam membuat sistem berbasis web nantinya menggunakan MYSQL sebagai tempat penyimpanan data atau database, MySQL (My Structured Query) merupakan salah satu jenis database server yang sangat terkenal dan banyak digunakan untuk membangun aplikasi web yang menggunakan database sebagai sumber dan pengolahan datanya. MySQL adalah software open source yang berarti free untuk digunakan. MYSQL sering digunakan dalam lingkungan linux dan windows. (Abdurahman, 2017)

\subsection{PHP}

PHP merupakan singkatan dari PHP Hypertext Preprocessor, merupakan Personal Home Page, pertama kali dibuat oleh Rasmus Lerdof pada tahun 1995 CMIIW. PHP: Hypertext Preprocessor merupakan bahasa skrip yang dapat ditanamkan atau disisipkan ke dalam HTML. PHP banyak dipakai untuk memprogram situs web dinamis. PHP dapat digunakan untuk membangun sebuah CMS. Untuk menjalankan PHP diperlukan Web Server seperti Apache, PHP Interpreter, MySQL sebagai database. (Krooks, 1991) 


\subsection{Adobe Dreamweaver CS5}

Adobe Dreamweaver merupakan sebuah editor profesional yang biasanya digunakan untuk mendesain web secara visual. Adobe Dreamweaver ialah sebuah software pertamakali digunakan oleh Website Desainer ataupun Website Programer dalam mengembangkan sebuah situs website, Adobe Dreamweaver memiliki ruang kerja, fasilitas serta kemampuan yang mampu meningkatkan produktifitas dan efektif dalam membuat desain ataupun membangun suatu situs website. (Yunarti \& Anggraini, 2016)

(Umar et al., 2018) melakukan peneltian dengan judul "Sistem Pendukung Keputusan dengan Metode AHP Untuk Penilaian Kompetensi Soft Skill Karyawan “. Tujuan penelitian ini adalah membantu penentu dalam menilaian soft skill karyawan dengan cara mencari nilai bobot untuk setiap kriteria, kemudian dilakukan proses perangkiangan yang akan menentukan alternatif yang optimal, yaitu soft skill karyawan yang tertinggi dan terendah.

(Suherdi et al., 2018) melakukan penelitian dengan judul " Penerapan Metode Ahp Dalam Sistem Pendukung Keputusan Kenaikan Pangkat Pegawai Di Badan Kepegawaian Dan Pengembagan Sumber Daya Manusia Kota Tangerang “. Tujuan dari penelitian ini dibuat sistem untuk menentukan layak tidaknya kenaikan pangkat diberikan kepada pegawai menggunakan sistem pendukung keputusan, dengan cara menentukan proses Kenaikan Pangkat menggunakan SPK dengan metode AHP dapat mempermudah dalam menentukan layak atau tidaknya pegawai mendapatkan kenaikan pangkat dan mempermudah dalam proses pembuatan laporan.

(Ahmad, 2018) melakukan penelitian dengan judul "Penggunaan Sistem Pendukung Keputusan Dengan Menggunakan Metode Analytical Hirarchy Process (AHP) Dalam Menyeleksi Kelayakan Penerima Beasiswa" . Tujuan dari penelitian ini adalah untuk menentukan dan menyeleksi calon penerima beasiswa dengan menggunakan metode Analytical Hirarchy Process (AHP), dimana kriteria di hitung bobotnya menggunakan metode AHP. Di harapkan dengan adanya sistem ini dapat membantu menentukan dan memutuskan calon penerima beasiswa yang berhak menerima beasiswa berdasarkan kriteria yang telah ditentukan

\section{Metode Penelitian}

Pada penelitian ini penulis menggunakan metode kuantitatif deskriptif dengan menggunakan data-data hasil observasi langsung dan hasil analisa pada perusahaan. Metode menganalisa data ditentukan berdasar landasan teori tentang sistem pendukung keputusan.

\subsection{Metode Pengembangan Sistem}

Metode pengembangan sistem yang digunakan dalam penelitian ini menggunakan metode waterfall, menurut Pressman, model waterfall merupakan model klasik yang sistematis, berurutan dalam membangun aplikasi. Nama model ialah "Linear Sequential Model". Model ini sering disebut juga dengan "classic life cycle" atau metode waterfall. Model ini menggunakan pendekatan secara sistematis serta berurutan. Disebut metode waterfall karena model ini berjalan sesuai tahapan yang dilalui, wajib menunggu sampai selesai tahap sebelumnya serta berjalan berurutan. (Widiyanto, 2018)

Berikut merupakan tahapan-tahapan Metode waterfall, sebagai berikut: (Hidayat et al., 
2017).

1) Analisis Proses pengumpulan kebutuhan sistem, dalam tahapan ini dilakukan secara intensif untuk menspesifikasikan kebutuhan perangkat lunak agar dapat dipahami perangakat lunak seperti apa yang dibutuhkan oleh user.

2) Design system merupakan proses ini fokus pada design pembuatan program perangkat lunak termasuk struktur data, arsitektur perangkat lunak, representasi antar muka, dan prosedur pengkodean.

3) Coding, yaitu Pembuatan kode program dari design yang sudah dibuat sebelumnya harus ditranslasikan ke dalam program perangkat lunak.

4) Testing, pada proses ini fokus pada perangkat lunak untuk menguji agar dapat memastikan bahwa semua bagian sudah diuji. Hal ini dilakukan agar dapat meminimalisir adanya error dan memastikan keluaran sesuai hasil yang diinginkan.

5) Maintenance, yaitu proses pemeliharaan dapat mengulangi proses pengembangan mulai dari analisis spesifikasi untuk perubahan perangkat lunak yang sudah ada, proses pemeliharaan ini biasanya jika terjadi perubahan struktur, baik dari segi software maupun hardware tapi tidak untuk membuat perangkat lunak baru.

\subsection{Metode Pengumpulan Data}

Metode pengumpulan data yang digunakan dalam penelitian ini, sebagai berikut :

1) Wawancara (interview) Merupakan proses pengumpulan data yang dilakukan dengan proses tanya jawab secara langsung dengan pihak yang terkait dengan penelitian yang dilakukan.

2) Studi pustakamerupakan proses mengumpulkan data - data dari buku - buku, jurnal internet dan sumber lainnya yang berhubungan dengan penulisan laporan penelitian ini.

3) Observasi yaitu melakukan peninjauan langsung terhadap objek penelitian serta mencatat hal - hal kejadian yang berhubungan dengan masalah yang diteliti untuk mendapatkan informasi yang dibutuhkan.

\subsection{Analytical Hierarchy Process (AHP)}

Analytical Hierarchy Process (AHP) adalah suatu metode atau model untuk pendukung keputusan yang dikembangkan oleh Thomas L. Saaty. Model pendukung keputusan akan menguraikan suatu masalah dari multi faktor atau multi kriteria yang kompleks untuk menjadi suatu hirarki, hirarki didefinisikan sebagai suatu representasi dari sebuah permasalahan yang kompleks dalam suatu struktur multi level dimana level yang pertama ialah tujuan, yang diikuti level faktor, kriteria, sub kriteria, hingga seterusnya ke bawah sampai level terakhir dari alternatif. Hirarki memiliki fungsi agar menguraikan suatu permasalahan ke dalam kelompok-kelompoknya sehingga nantinya dibuat menjadi suatu bentuk hirarki untuk menghasilkan Suatu permasalahan untuk terlihat lebih terstruktur (Alvioletta, Setyawan, \& Saputra, 2020).

Adapun prosedur atau langkah-langkah dalam metode Analytical Hierarchy Process (AHP) (Kusrini, 2007), anatara lain : 
1) Mengidentifikasi masalah dan menentukan solusi yang diinginkan, serta menyusun hierarki dari permasalahan yang dihadapi..

2) Menentukan prioritas elemen

a. Langkah pertama dalam menentukan prioritas elemen ialah membuat perbandingan pasangan, yaitu dengan membandingkan elemen secara berpasangan sesuai kriteria yang diberikan.

b. Matriks perbandingan berpasangan diisi menggunakan bilangan agar merepresentasikan kepentingan relative dari suatu elemen terhadap elemen yang lainnya.

3) Sintesis, merupakan Pertimbangan-pertimbangan terhadap perbandingan berpasangan disintesiskan untuk memperoleh keseluruhan prioritas. Adapun yang dilakukan dalam langkah ini sebagai berikut :

a. Menjumlahkan nilai-nilai dari setiap kolom pada matriks

b. Membagi setiap nilai dari kolom dengan total kolom yang bersangkutan untuk memperoleh normalisasi matriks.

c. Menjumlahkan nilai-nilai dari setiap baris dan membaginya dengan jumlah elemen untuk mendapatkan nilai rata-rata.

4) Mengukur Konsistensi. Langkah-langkah yang harus dilakukan adalah sebagai berikut :

a. Kalikan setiap nilai pada kolom pertama dengan prioritas relative elemen pertama, nilai pada kolom kedua dengan prioritas relative elemen kedua dan seterusnya

b. Jumlahkan setiap baris

c. Hasil dari penjumlahan baris dibagi dengan elemen prioritas relatif yang bersangkutan

d. Jumlahkan hasil bagi di atas dengan banyaknya elemen yang ada, hasilnya disebut $\lambda$ maks

5) Menghitung Consistency Indeks CI dengan rumus:

$\mathrm{CI}=(\lambda \operatorname{maks}-\mathrm{n}) /(\mathrm{n}-1)$

Dimana :

$\mathrm{CI}=$ Consistency Index

$\mathrm{n}=$ banyak elemen

6) Hitung Rasio Konsistensi/Consistency Ratio (CR) dengan rumus:

$\mathrm{CR}=\mathrm{CI} / \mathrm{IR}$

Dimana :

$\mathrm{CR}=$ Consistency Ratio

$\mathrm{CI}=$ Consistency Index 
$\mathrm{IR}=$ Index Random Consistency

(Nilai IR dapat dilihat pada Tabel 1. dibawah ini)

Tabel 1. Nilai Index Random Consistency (IR)

\begin{tabular}{cc}
$\begin{array}{c}\text { Ukuran } \\
\text { Matriks }\end{array}$ & \multicolumn{1}{l}{$\begin{array}{l}\text { Indeks } \\
\text { Random (IR) }\end{array}$} \\
\hline 1,2 & 0.00 \\
\hline 3 & 0,58 \\
\hline 4 & 0,90 \\
\hline 5 & 1,12 \\
\hline 6 & 1,24 \\
\hline 7 & 1,32 \\
\hline 8 & 1,41 \\
\hline 9 & 1,45 \\
\hline 10 & 1,49
\end{tabular}

7) Memeriksa konsistensi hierarki. Jika nilainya lebih dari $10 \%$, maka penilaian data judgment harus diperbaiki. Namun jika rasio konsistensi (CI/IR) kurang atau sama dengan 0.1 , maka hasil perhitungan bisa dinyatakan benar.

\section{Hasil dan Pembahasan}

Proses penilaian kinerja karyawan yang digunakan oleh PT Manggala Usaha Manunggal nantinya terbagi menjadi 2 (dua) yaitu penilaian untuk karyawan kontrak dan penilaian untuk karyawan tetap. Adapun kriteria-kriteria penilaian kinerja karyawan, sebagai berikut :

Tabel 2. Kriteria Penilaian

\section{Kriteria Karyawan Tetap}

Kualitas kerja

Kuantitas kerja

\section{Kriteria Karyawan Kontrak}

Pengetahuan dan keterampilan kerja

Kualitas kerja

Hubungan dan kerjasaa dalam Kuantitas kerja

pekerjaan

Kehadiran kerja

Hubungan

dan

kerjasama dalam 


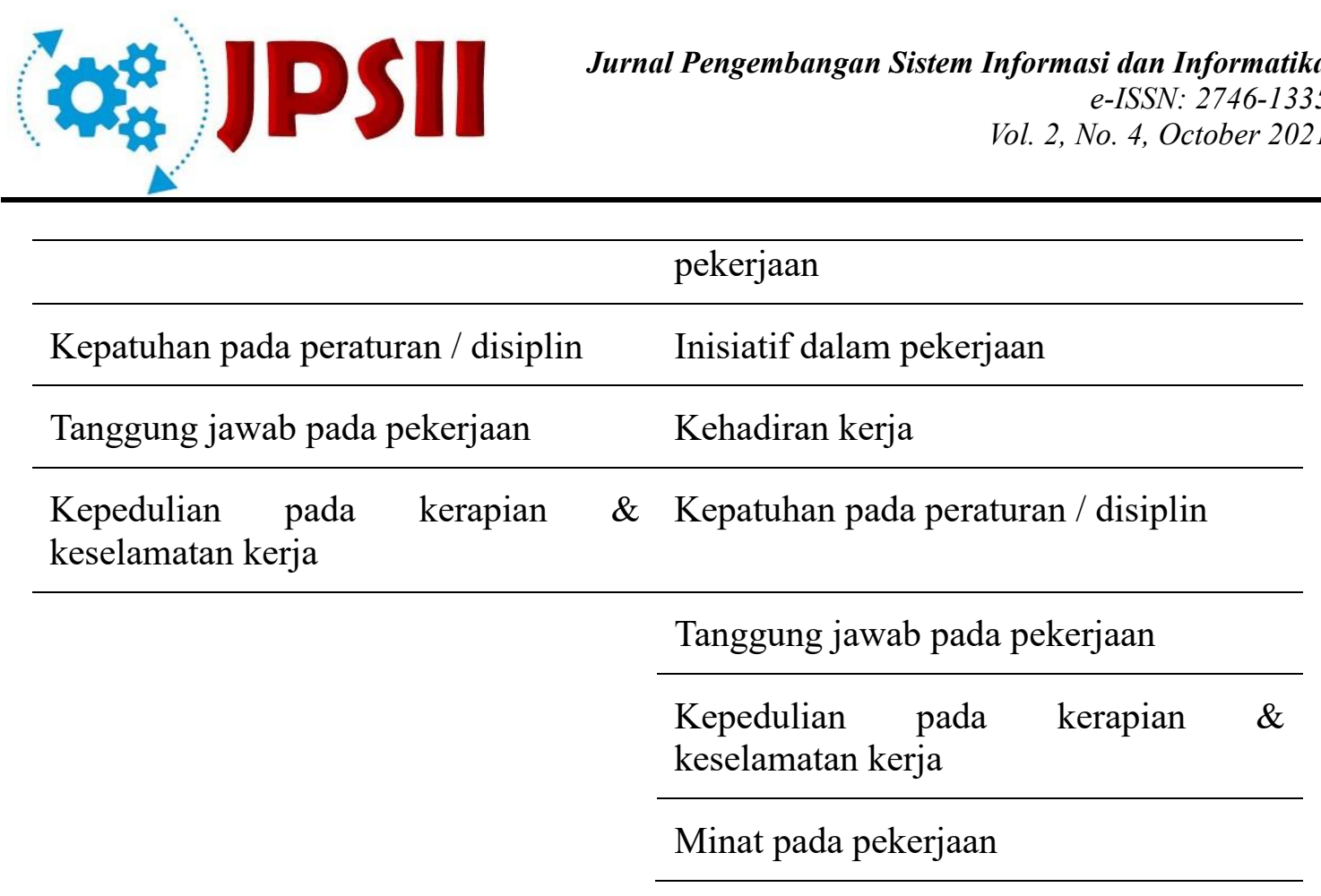

Kriteria diatas sudah ditentukan oleh pihak perusahaan dan merupakan parameter yang sangat relevan dalam proses perhitungan penilaian kinerja. Sehingga dibutuhkan evaluasi untuk membandingkan bobot kriteria penilaian. Evaluasi dilakukan dengan menggunakan metode AHP untuk menghitung bobot masing-masing kriteria agar dapat mengetahui bobot prioritas yang paling tinggi.

\subsection{Simulasi Penerapan Metode Analytical Hierarchy Process (AHP)}

\section{Mengidentifikasi Masalah}

Dalam proses mengidentifikasi masalah pada tahap ini untuk menentukan tujuan, kriteria dan alternatif yang ada, anatara lain :

- Tujuan :Penilaian kinerja karyawan terbaik

- Kriteria :Kualitas kerja (K1), kuantitas kerja (K2), hubungan dan kerjasama dalam pekerjaan (K3), kehadiran kerja (K4), kepatuhan pada peraturan / disiplin (K5), tanggung jawab pada pekerjaan (K6), kepedulian pada kerapian \& keselamatan kerja (K7).

- Aternatif :Karyawan tetap

2. Membuat struktur hirarki

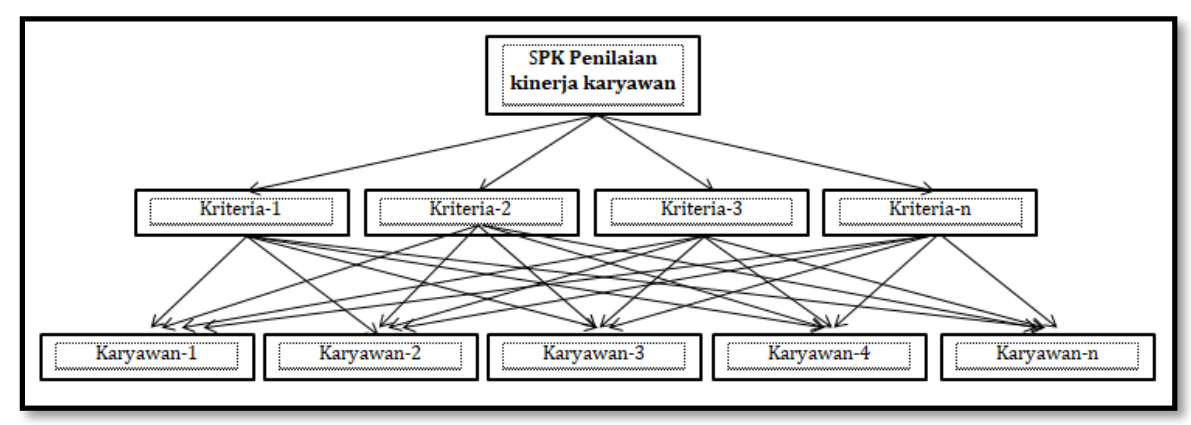

Gambar 1. Struktur Hirarki Penilaian Kinerja Karyawan

3. Sintesis 
Dalam proses sintesis dilakukan perhitungan sebagai pertimbang terhadap perbandingan berpasangan disintesiskan untuk memperoleh keseluruhan prioritas.

Tabel 3. Matriks perbandingan kriteria penilaian karyawan

\begin{tabular}{crrrrrrr}
\hline Kriteria & $\mathbf{k 1}$ & $\mathbf{k 2}$ & $\mathbf{k 3}$ & $\mathbf{k 4}$ & $\mathbf{k 5}$ & $\mathbf{k 6}$ & $\mathbf{k 7}$ \\
\hline $\mathbf{k 1}$ & 1 & 1 & 3 & 1 & 2 & 1 & 1 \\
\hline $\mathbf{k 2}$ & 1 & 1 & 3 & 1 & 1 & 1 & 2 \\
\hline $\mathbf{k 3}$ & 0.333333 & 0.333333 & 1 & 1 & 2 & 1 & 3 \\
\hline $\mathbf{k 4}$ & 1 & 1 & 1 & 1 & 2 & 2 & 2 \\
\hline $\mathbf{k 5}$ & 0.5 & 1 & 0.5 & 0.5 & 1 & 1 & 2 \\
\hline $\mathbf{k 6}$ & 1 & 1 & 1 & 0.5 & 1 & 1 & 2 \\
\hline $\mathbf{k} 7$ & 1 & 0.5 & 0.333333 & 0.5 & 0.5 & 0.5 & 1 \\
\hline Jumlah awal & 5.833333 & 5.833333 & 9.833333 & 5.5 & 9.5 & 7.5 & 13 \\
\hline
\end{tabular}

Selanjutnya menghitung nilai normalisasi matriks pada tabel 3. dengan cara mengalikan kolom dengan jumlah kolom (Jumlah awal). dari perhitungan diatas Maka didapat tabel normalisasi penilaian kinerja dibawah ini.

Tabel 4. Normalisasi matriks kriteria penilaian karyawan

\begin{tabular}{llllllll}
\hline Kriteria & $\mathbf{k} 1$ & $\mathbf{k} 2$ & $\mathbf{k 3}$ & $\mathbf{k} 4$ & $\mathbf{k 5}$ & $\mathbf{k} 6$ & $\mathbf{k} 7$ \\
\hline $\mathbf{k 1}$ & 0.171429 & 0.171429 & 0.305085 & 0.181818 & 0.210526 & 0.133333 & 0.076923 \\
\hline $\mathbf{k 2}$ & 0.171429 & 0.171429 & 0.305085 & 0.181818 & 0.105263 & 0.133333 & 0.153846 \\
\hline $\mathbf{k 3}$ & 0.057143 & 0.057143 & 0.101695 & 0.181818 & 0.210526 & 0.133333 & 0.230769 \\
\hline $\mathbf{k 4}$ & 0.171429 & 0.171429 & 0.101695 & 0.181818 & 0.210526 & 0.266667 & 0.153846 \\
\hline $\mathbf{k 5}$ & 0.085714 & 0.171429 & 0.050847 & 0.090909 & 0.105263 & 0.133333 & 0.153846 \\
\hline $\mathbf{k 6}$ & 0.171429 & 0.171429 & 0.101695 & 0.090909 & 0.105263 & 0.133333 & 0.153846 \\
\hline $\mathbf{k 7}$ & 0.171429 & 0.085714 & 0.033898 & 0.090909 & 0.052632 & 0.066667 & 0.076923
\end{tabular}

Selanjutnya jumlahkan nilai pada baris, lalu jumlahkan hasil penjumlahan secara keseluruhan.Nilai bobot dihasilkan dengan membagi nilai penjumlahan masing-masing baris dengan total keseluruhan.

Tabel 5. Bobot Normalisasi untuk perbandingan kriteria 


\begin{tabular}{ccccccccrr}
\hline $\begin{array}{c}\text { Kriter } \\
\text { ia }\end{array}$ & $\mathbf{k}$ 1 & $\mathbf{k 2}$ & $\mathbf{k 3}$ & $\mathbf{k 4}$ & $\mathbf{k 5}$ & $\mathbf{k 6}$ & $\mathbf{k} 7$ & $\begin{array}{r}\text { Jumla } \\
\mathbf{h}\end{array}$ & Bobot \\
\hline & 0.1714 & 0.1714 & 0.3050 & 0.1818 & 0.2105 & 0.1333 & 0.0769 & 1.2505 & 0.1786 \\
$\mathbf{k 1}$ & 29 & 29 & 85 & 18 & 26 & 33 & 23 & 43 & 49 \\
\hline & 0.1714 & 0.1714 & 0.3050 & 0.1818 & 0.1052 & 0.1333 & 0.1538 & 1.2222 & 0.1746 \\
$\mathbf{k 2}$ & 29 & 29 & 85 & 18 & 63 & 33 & 46 & 03 & 00 \\
\hline & 0.0571 & 0.0571 & 0.1016 & 0.1818 & 0.2105 & 0.1333 & 0.2307 & 0.9724 & 0.1389 \\
$\mathbf{k 3}$ & 43 & 43 & 95 & 18 & 26 & 33 & 69 & 28 & 18 \\
\hline & 0.1714 & 0.1714 & 0.1016 & 0.1818 & 0.2105 & 0.2666 & 0.1538 & 1.2574 & 0.1796 \\
$\mathbf{k} 4$ & 29 & 29 & 95 & 18 & 26 & 67 & 46 & 09 & 3 \\
\hline & 0.0857 & 0.1714 & 0.0508 & 0.0909 & 0.1052 & 0.1333 & 0.1538 & 0.7913 & 0.1130 \\
$\mathbf{k} 5$ & 14 & 29 & 47 & 09 & 63 & 33 & 46 & 42 & 49 \\
\hline & 0.1714 & 0.1714 & 0.1016 & 0.0909 & 0.1052 & 0.1333 & 0.1538 & 0.9279 & 0.1325 \\
$\mathbf{k} 6$ & 29 & 29 & 95 & 09 & 63 & 33 & 46 & 04 & 58 \\
\hline & 0.1714 & 0.0857 & 0.0338 & 0.0909 & 0.0526 & 0.0666 & 0.0769 & 0.5781 & 0.0825 \\
$\mathbf{k} 7$ & 29 & 14 & 98 & 09 & 32 & 67 & 23 & 72 & 96 \\
\hline & & & & & & & & 7 & 1 \\
\hline
\end{tabular}

\section{Mengukur Rasio Konsistensi}

Rasio konsistensi digunakan untuk mengetahui tingkat konsistensi penilaian perbandingan kriteria.

- Menentukan nilai $\lambda$ maks

Nilai $\lambda$ maks diperoleh dengan mengalikan hasil penjumlahan awal setiap baris pada matriks perbandingan berpasangan dengan bobot hasil normalisasi.

$\lambda m a k s=7.55651$

- Menghitung Indeks Konsistensi (CI)

$\mathrm{CI}=(\lambda$ maks $-\mathrm{n}) /(\mathrm{n}-1)$

$\mathrm{CI}=(7.55651-7) /(7-1)$

$\mathrm{CI}=0.09275$

- Menghitung Rasio Konsistensi (CR)

$\mathrm{CR}=\mathrm{CI} / \mathrm{IR}$

$\mathrm{CR}=0.09275 / 1.32$

$\mathrm{CR}=0.07027$

Karena $\mathrm{CR}<0,1$ maka preferensi pembobotan adalah konsisten. Jadi nilai kriteria di atas bisa dipakai. 
Maka hasil nilai bobot kriteria penilaian kinerja karyawan, sebagai berikut :

Tabel 6. Nilai Bobot Kriteria Penilaian Karyawan

\begin{tabular}{lc}
\multicolumn{1}{c}{ Kriteria } & Bobot \\
\hline Kualitas kerja (K1) & 0.178649 \\
\hline Kuantitas kerja (K2) & 0.174600 \\
\hline Hubungan dan kerjasaa dalam pekerjaan (K3) & 0.138918 \\
\hline Kehadiran kerja (K4) & 0.179630 \\
\hline Kepatuhan pada peraturan / disiplin (K5) & 0.113049 \\
\hline Tanggung jawab pada pekerjaan (K6) & 0.132558 \\
\hline Kepedulian pada kerapian \& keselamatan kerja (K7) & 0.082596
\end{tabular}

\subsection{Proses Hasil Penilaian Kinerja}

Dalam proses penilaian pihak perusahaan memberikan bobot nilai untuk sistem penilaian, sebagai berikut :

Baik sekali $=10 / 9$

Baik $=8 / 7$

Cukup $=6 / 5$

Kurang $\quad=4 / 3$

Kurang sekali $=2 / 1$

Dimana nilai dari masing-masing karyawan kemudian diproses dengan menggunakan bobot dari kriteria di atas sehingga akan didapat hasil perhitungan dan perankingan sesuai dengan metode AHP.

Tabel 7. Contoh Nilai Dari Masing-masing Karyawan

\begin{tabular}{|c|c|c|c|c|c|c|c|c|c|c|c|c|c|c|}
\hline \multirow{3}{*}{ NIK } & \multirow{3}{*}{ Nama } & \multirow{3}{*}{ Departemen } & \multicolumn{12}{|c|}{ Nilai } \\
\hline & & & \multicolumn{3}{|c|}{ K1 } & \multicolumn{3}{|c|}{ K2 } & \multicolumn{3}{|c|}{ K3 } & \multicolumn{3}{|c|}{ K4 } \\
\hline & & & 1 & 2 & 3 & 1 & 2 & 3 & 1 & 2 & 3 & 1 & 2 & 3 \\
\hline 1800357 & Ade pratama putra & Plant & 8 & 9 & 8 & 7 & 8 & 7 & 8 & 8 & 8 & 9 & 9 & 9 \\
\hline 1800977 & Randa sugara & Hse & 8 & 8 & 9 & 8 & 8 & 8 & 9 & 9 & 8 & 8 & 9 & 9 \\
\hline 1801169 & Akbar alpin & Logistik & 9 & 8 & 7 & 8 & 7 & 7 & 8 & 8 & 8 & 10 & 9 & 10 \\
\hline 1900323 & Milsa yadi & Engineering & 8 & 8 & 8 & 8 & 8 & 7 & 8 & 8 & 8 & 10 & 9 & 9 \\
\hline
\end{tabular}




\begin{tabular}{lllllllllllllll}
2000229 & Mia eptita & Hcga & 9 & 9 & 9 & 8 & 8 & 9 & 8 & 9 & 8 & 10 & 10 & 10 \\
\hline 2021510 & M. Andi juliawan & Produksi & 8 & 9 & 9 & 8 & 8 & 8 & 9 & 9 & 8 & 10 & 9 & 10 \\
\hline
\end{tabular}

Tabel 8. Contoh Nilai Dari Masing-masing Karyawan

\begin{tabular}{|c|c|c|c|c|c|c|c|c|c|c|c|}
\hline \multirow{3}{*}{ NIK } & \multirow{3}{*}{ Nama } & \multirow{3}{*}{ Departemen } & \multicolumn{9}{|c|}{ Nilai } \\
\hline & & & \multicolumn{3}{|c|}{ K5 } & \multicolumn{3}{|c|}{ K6 } & \multicolumn{3}{|c|}{ K7 } \\
\hline & & & 1 & 2 & 3 & 1 & 2 & 3 & 1 & 2 & 3 \\
\hline 1800357 & Ade pratama putra & Plant & 8 & 7 & 7 & 8 & 8 & 8 & 8 & 8 & 7 \\
\hline 1800977 & Randa sugara & Hse & 8 & 8 & 8 & 8 & 8 & 8 & 7 & 8 & 8 \\
\hline 1801169 & Akbar alpin & Logistik & 8 & 7 & 8 & 8 & 7 & 7 & 9 & 8 & 8 \\
\hline 1900323 & Milsa yadi & Engineering & 8 & 8 & 8 & 7 & 8 & 8 & 8 & 8 & 7 \\
\hline 2000229 & Mia eptita & Hcga & 9 & 9 & 8 & 9 & 8 & 8 & 8 & 8 & 8 \\
\hline 2021510 & M. Andi juliawan & Produksi & 8 & 9 & 9 & 8 & 9 & 9 & 8 & 9 & 8 \\
\hline
\end{tabular}

Langkah pertama, Jumlahkan nilai karyawan pada setiap kriteria dan dibagi dengan jumlah yang menilai, selanjutnya Jumlahkan setiap kriteria kebawah sehingga mendapatkan nilai jumlah awal.

Tabel 9. Jumlah nilai kriteria penilaian karyawan

\begin{tabular}{llrrrrrrr}
\hline \multirow{2}{*}{ NIK } & \multirow{2}{*}{ Nama } & \multicolumn{8}{c}{ Nilai } \\
\cline { 3 - 9 } & & K1 & K2 & K3 & K4 & K5 & K6 & K7 \\
\hline 1800357 & Ade pratama putra & 8.33 & 7.33 & 8 & 9 & 7.33 & 8 & 7.67 \\
\hline 1800977 & Randa sugara & 8.33 & 8 & 8.67 & 8.67 & 8 & 8 & 7.67 \\
\hline 1801169 & Akbar alpin & 8 & 7.33 & 8 & 9.67 & 7.67 & 7.33 & 8.33 \\
\hline 1900323 & Milsa yadi & 8 & 7.67 & 8 & 9.33 & 8 & 7.67 & 7.67 \\
\hline 2000229 & Mia eptita & 9 & 8.33 & 8.33 & 10 & 8.67 & 8.33 & 8 \\
\hline 2021510 & M. Andi juliawan & 8.67 & 8 & 8.67 & 9.67 & 8.67 & 8.67 & 8.33 \\
\hline & \multirow{2}{*}{ Jumlah awal } & 50.33 & 46.66 & 49.67 & 56.33 & 48.33 & 48 & 47.67 \\
\hline
\end{tabular}

Langkah kedua, melakukan Normalisasi Tabel 9 diatas.

Tabel 10. Normaliasi Matriks Penilaian Kinerja Karyawan 


\begin{tabular}{|c|c|c|c|c|c|c|c|c|}
\hline \multirow{2}{*}{ NIK } & \multirow{2}{*}{ Nama } & \multicolumn{7}{|c|}{ Nilai } \\
\hline & & K1 & $\mathrm{K} 2$ & $\mathrm{~K} 3$ & K4 & K5 & K6 & K7 \\
\hline \multirow{2}{*}{$\begin{array}{r}18003 \\
57\end{array}$} & \multirow{2}{*}{$\begin{array}{l}\text { Ade } \\
\text { putra }\end{array}$} & 0.1655 & 0.1571 & 0.1610 & 0.1597 & 0.1517 & 0.1666 & 0.1608 \\
\hline & & & 43 & 74 & 63 & 24 & 67 & 39 \\
\hline \multirow{2}{*}{$\begin{array}{r}18009 \\
77\end{array}$} & \multirow{2}{*}{ Randa sugara } & 0.1655 & 0.1714 & 0.1744 & 0.1538 & 0.1655 & 0.1666 & 0.1608 \\
\hline & & 63 & 29 & 97 & 46 & 17 & 67 & 39 \\
\hline \multirow{2}{*}{$\begin{array}{r}18011 \\
69\end{array}$} & \multirow{2}{*}{ Akbar alpin } & 0.1589 & 0.1571 & 0.1610 & 0.1715 & 0.1586 & 0.1527 & 0.1748 \\
\hline & & 40 & 43 & 74 & 98 & 21 & 78 & 25 \\
\hline \multirow{2}{*}{$\begin{array}{r}19003 \\
23\end{array}$} & \multirow{2}{*}{ Milsa yadi } & 0.1589 & 0.1642 & 0.1610 & 0.1656 & 0.1655 & 0.1597 & 0.1608 \\
\hline & & 40 & 86 & 74 & 80 & 17 & 22 & 39 \\
\hline \multirow{2}{*}{$\begin{array}{r}20002 \\
29\end{array}$} & \multirow{2}{*}{ Mia eptita } & 0.1788 & 0.1785 & 0.1677 & 0.1775 & 0.1793 & 0.1736 & 0.1678 \\
\hline & & 08 & 71 & 85 & 15 & 10 & 11 & 32 \\
\hline \multirow{2}{*}{$\begin{array}{r}20215 \\
10\end{array}$} & Andi & 0.1721 & 0.1714 & 0.1744 & 0.1715 & 0.1793 & 0.1805 & 0.1748 \\
\hline & juliawan & 85 & 29 & 97 & 98 & 10 & 56 & 25 \\
\hline
\end{tabular}

Langkah ketiga, yaitu perkalian normalisasi dengan bobot kriteria AHP pada Tabel 3.6.

Nilai bobot kriteria penilaian karyawan, anatara lain sebagai_berikut :

$$
\text { Kriteria }_{-}=\text {Normalisasi }^{*} \text { Bobot Kriteria AHP }
$$

Tabel 11. Hasil perkalian normalisasi dengan bobot kriteria AHP

\begin{tabular}{|c|c|c|c|c|c|c|c|c|}
\hline \multirow{2}{*}{ NIK } & \multirow{2}{*}{ Nama } & \multicolumn{7}{|c|}{ Nilai } \\
\hline & & K1 & $\mathrm{K} 2$ & K3 & K4 & $\mathrm{K} 5$ & K6 & $\mathrm{K} 7$ \\
\hline 1800357 & $\begin{array}{l}\text { Ade } \quad \text { pratama } \\
\text { putra }\end{array}$ & 0.029578 & 0.027437 & 0.022376 & 0.028698 & 0.017152 & 0.022093 & 0.013285 \\
\hline 1800977 & Randa sugara & 0.029578 & 0.029932 & 0.024241 & 0.027635 & 0.018712 & 0.022093 & 0.013285 \\
\hline 1801169 & Akbar alpin & 0.028394 & 0.027437 & 0.022376 & 0.030824 & 0.017932 & 0.020252 & 0.01444 \\
\hline 1900323 & Milsa yadi & 0.028394 & 0.028684 & 0.022376 & 0.029761 & 0.018712 & 0.021172 & 0.013285 \\
\hline 2000229 & Mia eptita & 0.031944 & 0.031179 & 0.023308 & 0.031887 & 0.020271 & 0.023013 & 0.013862 \\
\hline 2021510 & M. Andi juliawan & 0.030761 & 0.029932 & 0.024241 & 0.030824 & 0.020271 & 0.023934 & 0.01444 \\
\hline
\end{tabular}

Langkah keempat, jumlahkan semua hasil perkalian normalisasi dengan bobot kriteria AHP diatas, dan mendapatkan hasil akhir yaitu perangkiangan karyawan terbaik.

Tabel 12. Hasil perangkingan penilaian karyawan 


\begin{tabular}{|c|c|c|c|c|}
\hline NIK & Nama & Departemen & $\begin{array}{l}\text { Jumlah } \\
\text { nilai }\end{array}$ & Rangking \\
\hline 2000229 & Mia eptita & Hcga & 0.175464 & 1 \\
\hline 2021510 & M. Andi juliawan & Produksi & 0.174402 & 2 \\
\hline 1800977 & Randa sugara & Hse & 0.165475 & 3 \\
\hline 1900323 & Milsa yadi & Engineering & 0.162385 & 4 \\
\hline 1801169 & Akbar alpin & Logistik & 0.161656 & 5 \\
\hline 1800357 & Ade pratama putra & Plant & 0.160619 & 6 \\
\hline
\end{tabular}

Jadi didapatkan dengan NIK : 2000229 atas Nama : Mia Eptita dengan Bobot nilai : 0.175464 rangking pertama pada contoh proses penilaian kinerja karyawan menggunakan metode AHP (Analtytical Hierarchy Process)

\subsection{Web Sistem Pendukung Keputusan Menggunakan Metode AHP}

1) Halaman Daftar Karyawan

Pada halaman ini admin dan pengawas dapat melihat daftar karyawan serta dapat menginput data karyawan baru, mengedit data karyawan lama serta menghapus data.

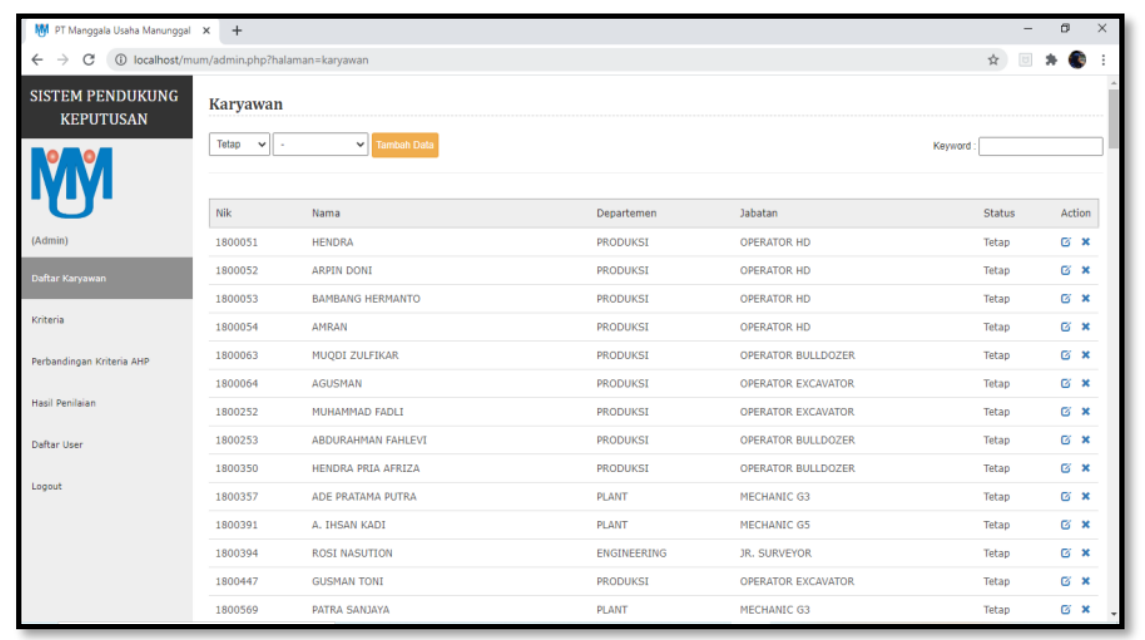

Gambar 2. Halaman Daftar Karyawan

2) Halaman Kriteria

Pada halaman ini admin dapat melihat kriteria yang menjadi proses penilaian kinerja, serta dapat menambahkan kriteria, mengedit dan menghapus kriteria. 

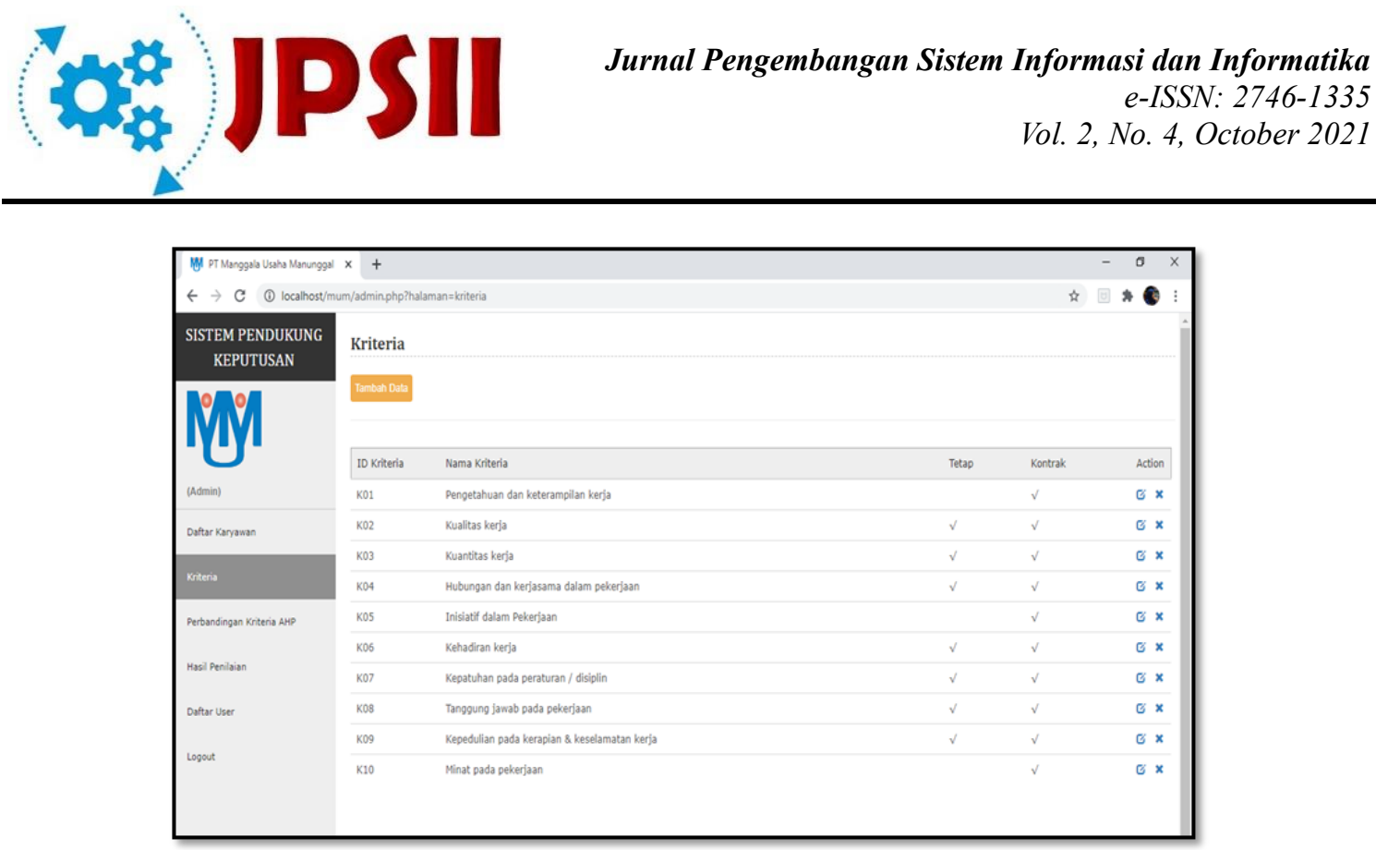

Gambar 3. Halaman Kriteria

3) Halaman Perbandingan Kriteria AHP

Halaman ini digunakan admin untuk menginput perbandingan kriteria penilaian, sehingga mendapatkan hasil pembobotan dari setiap kriteria. Dimana admin berkonsultasi dengan pimpinan mengenai tingkat kepentingan kriteria, lalu hasil konsultasi tersebut diinput kedalam form kriteria. Setelah diinput jika nilai consistency ratio (CR) tidak konsisten maka admin melakukan konsultasi ulang, konsultasi dilakukan hingga nilainya konsisten.

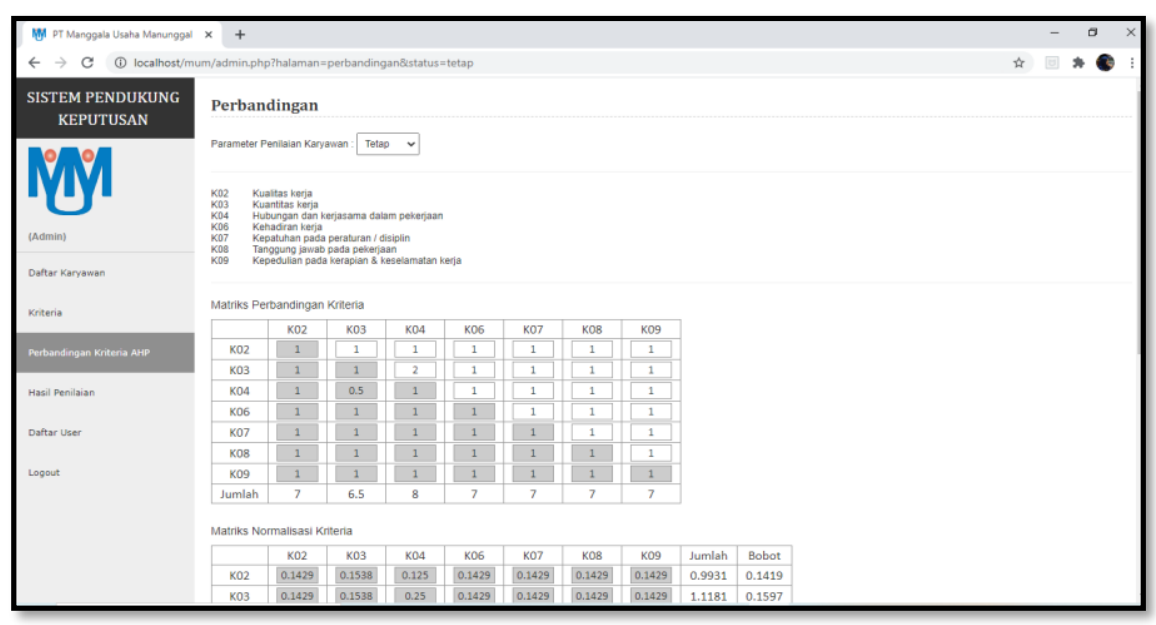

Gambar 4. Halaman Perbandingan Kriteria AHP

4) Halaman Penilaian

Halaman ini digunakan oleh pengawas untuk menginput data penilaian karyawan berdasarkan parameter penilaian yang sudah ditentukan. 

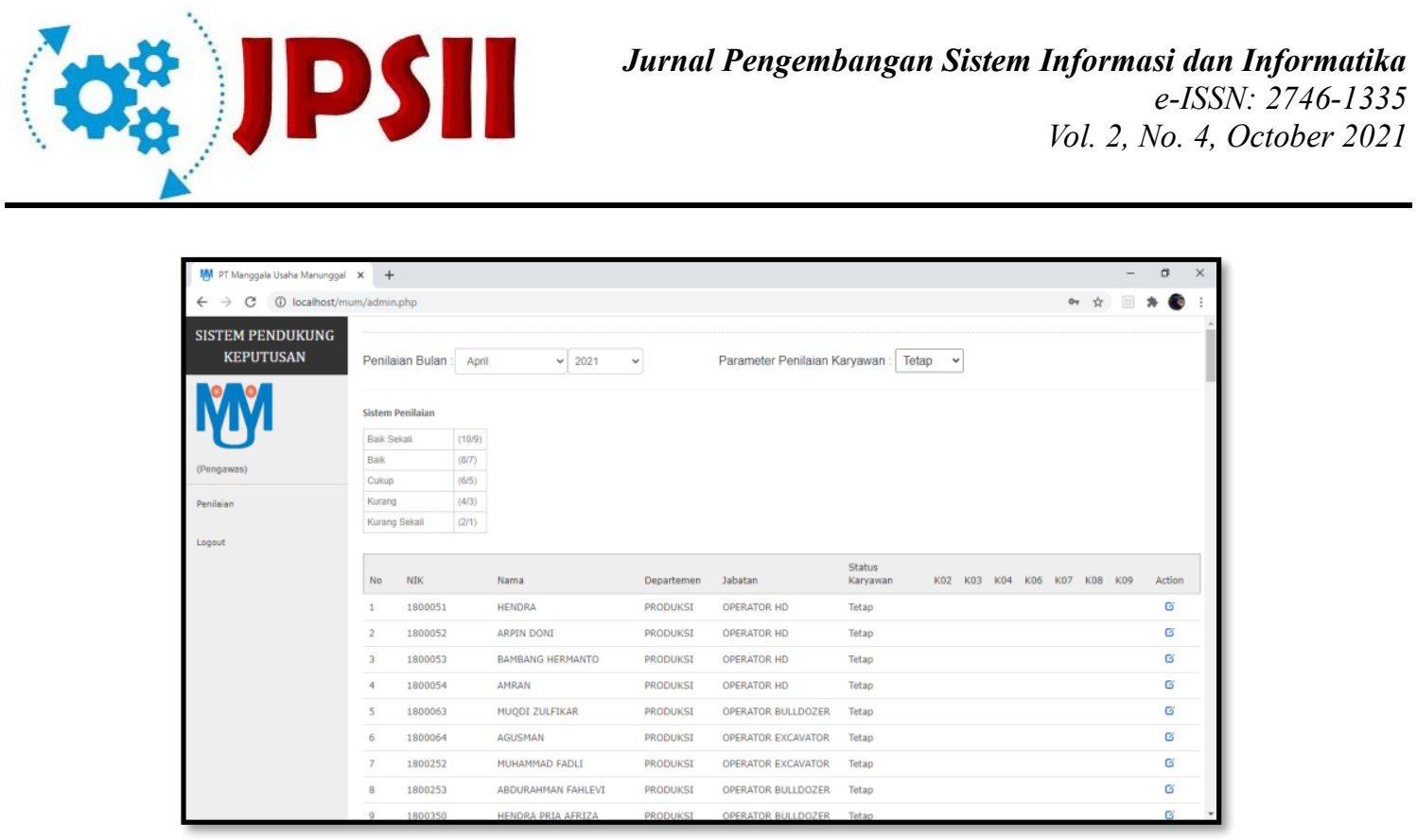

Gambar 5. Halaman Penilaian

5) Halaman Hasil Penilaian

Halaman ini digunakan oleh admin untuk melihat data Hasil Penilaian karyawan berdasarkan skor bobot penilaian. Halaman ini menampilkan hasil proses perhitungan dan juga mempunyai fitur untuk mendownload file laporan hasil penilaian karyawan sehingga dapat dicetak secara berkala.

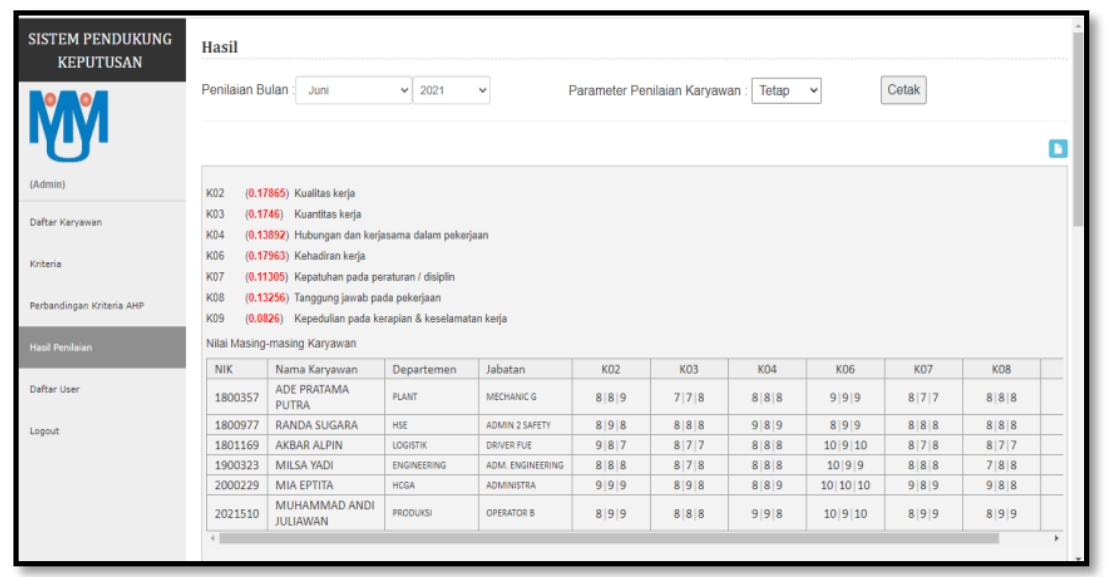

Gambar 6. Halaman Hasil Penilaian

6) Halaman Daftar User

Gambar dibawah ini digunakan oleh admin untuk dapat menambahkan data user, mengganti password, mengedit, serta menghapus data user. 

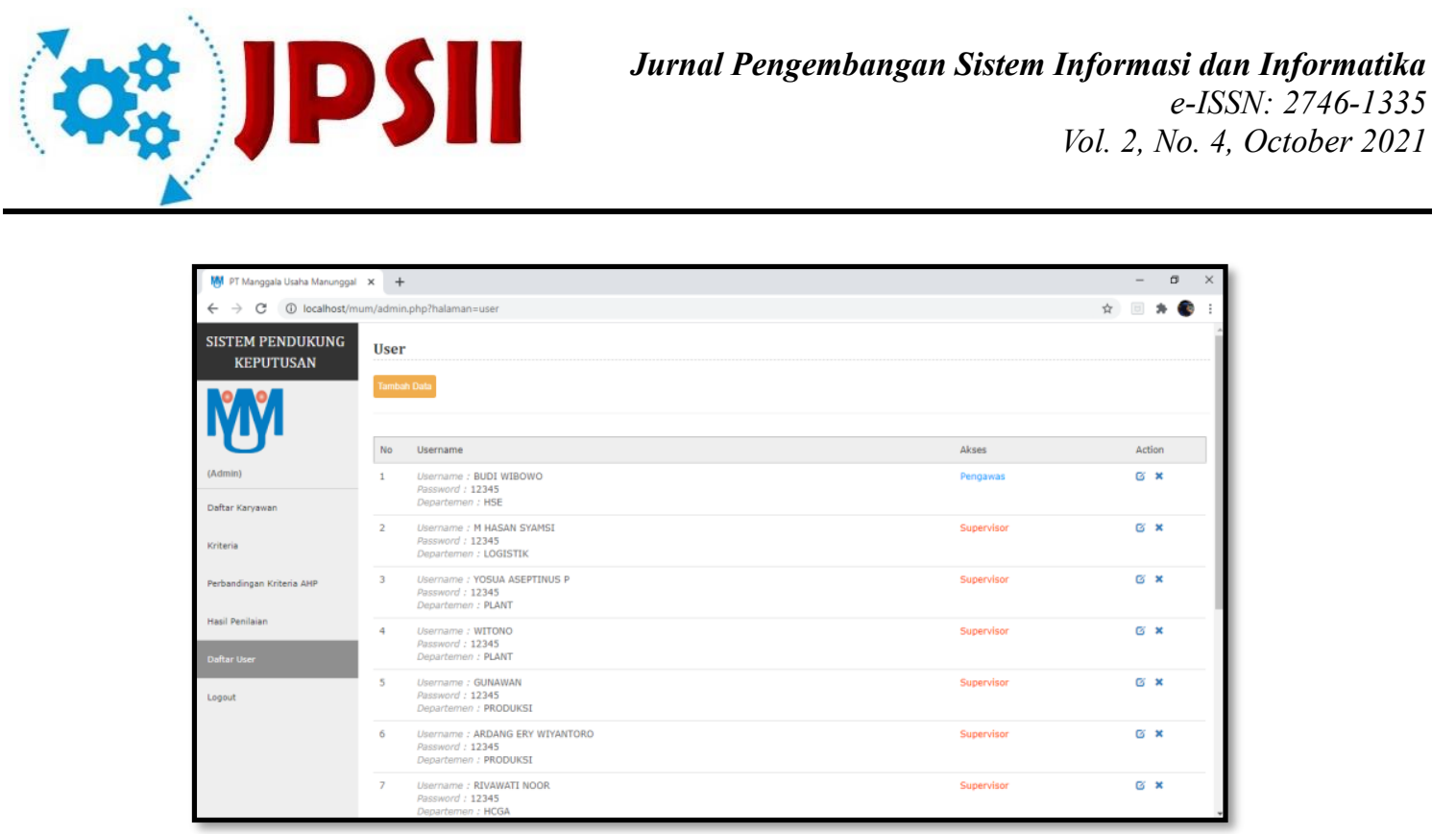

Gambar 7. Halaman Daftar User

7) Halaman Laporan Hasil Penilaian

Halaman ini digunakan oleh pimpinan agar dapat melihat hasil penilaian karyawan secara berkala. Dimana pada halaman ini terdapat fitur untuk download / mencetak file laporan hasil penilaian.

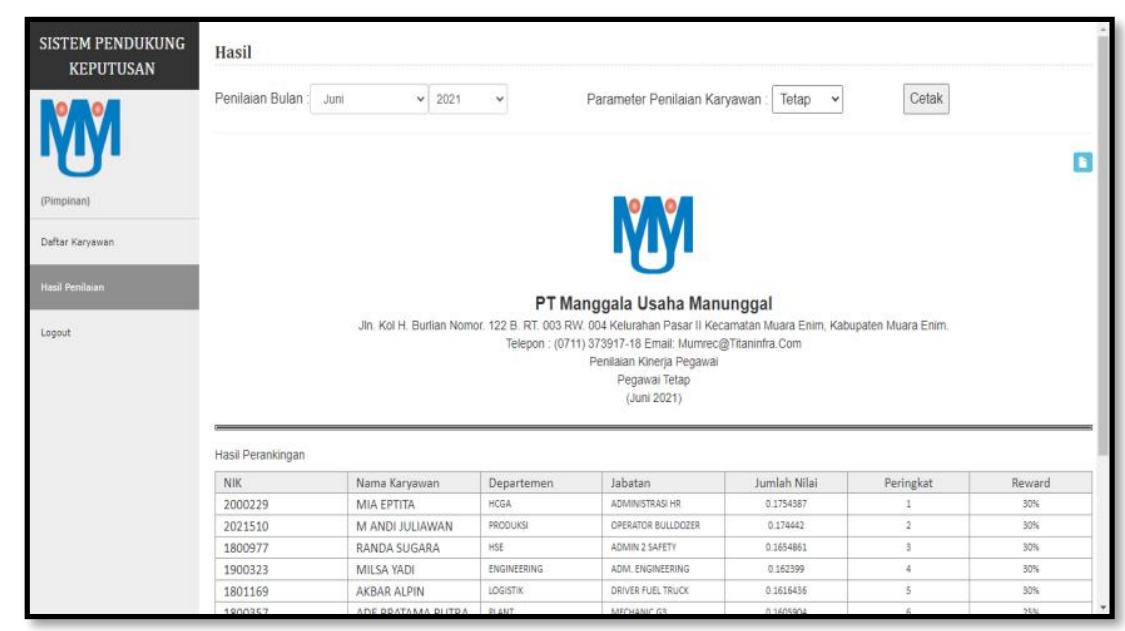

Gambar 8. Halaman Laporan Hasil Penilaian

\section{Kesimpulan}

Berdasarkan uraian yang telah dikemukakan pada bab sebelumnya, maka dapat disimpulkan sebagai berikut :

1. Penelitian ini menghasilkan sistem pendukung keputusan yang dapat mempermudah perusahaan melakukan penilaian terhadap kinerja karyawan pada PT Manggala Usaha Manunggal.

2. Sistem ini dapat mempermudah admin dalam mengelola data karyawan, data kriteria, dan data user.

3. Sistem ini mempermudah pimpinan dalam mengecek data karyawan yang mendapatkan perangkingan karyawan terbaik serta dapat mencetak file data penilaian secara berkala. 


\section{Referensi}

Antoni, D., Herdiansyah, M. I., Akbar, M., \& Sumitro, A. (2021). Pengembangan Infrastruktur Jaringan Untuk Meningkatkan Pelayanan Publik di Kota Palembang. JURNAL MEDIA INFORMATIKA BUDIDARMA, 5(4), 1652-1659.

Antoni, D., Jie, F., \& Abareshi, A. (2020). Critical factors in information technology capability for enhancing firm's environmental performance: case of Indonesian ICT sector. International Journal of Agile Systems and Management, 13(2), 159-181.

Antoni, D., \& Akbar, M. (2019). E-supply chain management value concept for the palm oil industry. Jurnal Sistem Informasi, 15(2), 15-29.

Antoni, D., Fikari, D., \& Akbar, M. (2018). The readiness of palm oil industry in enterprise resource planning. Telkomnika, 16(6), 2692-2702.

Fauzi, F., Dencik, A. B., \& Asiati, D. I. (2019). Metodologi Penelitian untuk manajemen dan akuntansi. Jakarta: Salemba Empat.

Hidayat, R., Marlina, S., \& Utami, L. D. (2017). Perancangan Sistem Informasi Penjualan Barang Handmade Berbasis Website Dengan Metode Waterfall. Simnasiptek, 176-183.

Widiyanto, W. W. (2018). Analisa Metodologi Pengembangan Sistem Dengan Perbandingan Model Perangkat Lunak Sistem Informasi Kepegawaian Menggunakan Waterfall Development Model, Model Prototype, Dan Model Rapid Application Development (Rad). Jurnal Informa Politeknik Indonusa Surakarta ISSN, 4(1), 34-40. http://www.informa.poltekindonusa.ac.id/index.php/informa/article/view/34

Abdurahman, M. (2017). Sistem Informasi Pengolahan Data Pembelian Dan Penjualan Pada Toko Koloncucu Ternate. IJIS - Indonesian Journal On Information System, 2(1). https://doi.org/10.36549/ijis.v2i1.22

Ahmad, R. (2018). PENGGUNAAN SISTEM PENDUKUNG KEPUTUSAN DENGAN MENGGUNAKAN METODE ANALYTICAL HIRARCHY PROCESS ( AHP ) DALAM MENYELEKSI KELAYAKAN PENERIMA BEASISWA. 2(1), 28-33.

Heriyanto, Y. (2018). Perancangan Sistem Informasi Rental Mobil Berbasis Web Pada PT.APM Rent Car. Jurnal Intra-Tech, 2(2), 64-77.

Krooks, D. A. (1991). The 'Hero on the Beach' in the Old Saxon Heliand? American Journal of Germanic Linguistics and Literatures, 3(2), 161-174. https://doi.org/10.1017/S104082070000069X

[Kusrini, M. K. (2007). Konsep Dan Aplikasi Sistem Pendukung Keputusan. In Penerbit Andi.

\section{Copyrights}

Copyright for this article is retained by the author(s), with first publication rights granted to the journal.

This is an open-access article distributed under the terms and conditions of the Creative Commons Attribution license (http://creativecommons.org/licenses/by/4.0/) 